\title{
Transmissible gastroenteritis virus infection decreases arginine uptake by downregulating CAT-1 expression
}

\author{
Lu Xia, Lei Dai and Qian Yang*
}

\begin{abstract}
Transmissible gastroenteritis virus (TGEV) is a coronavirus that causes severe diarrhea in suckling piglets. TGEV primarily targets and infects porcine intestinal epithelial cells, which play an important role in nutrient absorption. However, the effects of TGEV infection on nutrient absorption in swine have not yet been investigated. In this study, we evaluated the impact of TGEV infection on arginine uptake using the porcine small intestinal epithelial cell line IPEC-J2 as a model system. High performance liquid chromatography (HPLC) analyses showed that TGEV infection leads to reduced arginine uptake at 48 hours post-infection (hpi). Expression of cationic amino acid transporter 1 (CAT-1) was attenuated as well. TGEV infection induced activation of phospho-protein kinase C a ( $p$-PKC a), phospho-epidermal growth factor receptor (p-EGFR), and enhanced the expression of caveolin-1, all of which appear to be involved in down-regulating arginine uptake and CAT-1 expression. These results illuminate the relationship between TGEV infection and nutrient absorption, and further our understanding of the mechanisms of TGEV infection.
\end{abstract}

\section{Introduction}

Transmissible gastroenteritis (TGE) is a highly contagious enteric disease of pigs caused by TGE virus (TGEV), with mortality rates as high as $100 \%$ in piglets less than 2 weeks old [1,2]. TGEV infects the epithelial cells of the intestinal tract, resulting in villus atrophy and impaired absorption of nutrition [3, 4]. The porcine small intestinal epithelial cell line IPEC-J2 is an intestinal columnar epithelial cell line that was isolated from the mid-jejunum of a neonatal piglet [5]. IPEC-J2 cells are used for in vitro investigations of swine viruses and nutrition $[6,7]$.

Arginine, an amino acid that is essential in neonates, is synthesized by enterocytes $[8,9]$. Arginine is one of the most metabolically versatile amino acids, and serves as a precursor for synthesis of protein, nitric oxide, creatine, polyamines, agmatine, and urea, which mediate important regulatory functions that affect nutrient metabolism

*Correspondence: zxbyq@njau.edu.cn MOE Joint International Research Laboratory of Animal Health and Food Safety, College of Veterinary Medicine, Nanjing Agricultural University, Weigang 1, Nanjing, Jiangsu 210095, China and immune responses [10-13]. The cellular uptake of arginine is mediated primarily by proteins in the cationic amino acid transporter (CAT) family [14]. Abundant evidence indicates that this family is important for maintaining arginine homeostasis and overall protein nutrition in the body [15-17].

The molecular mechanism underlying CAT- 1 expression is associated with the activation of the intracellular signal transduction molecule protein kinase C (PKC). $\mathrm{PKC}$ is located in close proximity to CAT-1 in the caveola and regulates CAT- 1 activity $[18,19]$. PKC has been identified as a family of protein kinase enzymes that participate in many cellular processes, and classical isoforms of PKC are involved in the regulation of the CAT- 1 transporter $[20,21]$. The role of PKC- $\alpha$ in the regulation of arginine transport has been investigated in different cell types [22, 23].

Intestinal arginine transport is regulated by local as well as systemic factors such as growth factors, differentiation states, and luminal substrates [24]. Several growth factors, including epidermal growth factor (EGF) and 
transforming growth factor $\alpha$ (TGF- $\alpha$ ), elicit their functions by binding to EGF receptors (EGFR) and instigating an intracellular PKC signal transduction cascade [25, 26]. EGFR is a transmembrane protein and is expressed on the surface of many different cell types. Previous studies in our laboratory have shown that EGFR promotes TGEV entry into intestinal epithelial cells by regulating cofilin activity, and that both clathrin- and caveolin-mediated endocytosis are important for TGEV and EGFR internalization $[27,28]$.

Most studies have focused on the pathogenesis of TGEV infection. However, little is known about the impact of TGEV infection on nutrient uptake from the small intestine, especially for amino acids. We therefore evaluated TGEV infection on arginine uptake and the signaling pathways involved in arginine uptake in IPECJ2 cells.

\section{Materials and methods \\ Cell lines}

IPEC-J2 cells were purchased from the DSMZ (Germany), and HEK293T cells were purchased from the American Type Culture Collection (ATCC). Both cell lines were cultured in Dulbecco's modified Eagle's medium (DMEM, Gibco) with $10 \%$ fetal bovine serum (FBS, Gibco), using an incubator maintained at $37^{\circ} \mathrm{C}$ in $5 \% \mathrm{CO}_{2}$.

\section{Viral infection}

TGEV strain SHXB (GenBank: KP202848.1) was provided by the Jiangsu Academy of Agricultural Sciences (JAAS, Jiangsu Province, China) [29]. For experimental assays, cells were infected with TGEV at a multiplicity of infection (MOI) of 3 for $1 \mathrm{~h}$ at $37{ }^{\circ} \mathrm{C}$ in serum-free medium and washed with phosphate-buffered saline (PBS, pH 7.2) three times to remove unbound virus. Cells were then cultured in maintenance medium (DMEM containing $2 \% \mathrm{FBS}$ ).

\section{RNA extraction and real-time PCR analysis}

Total RNA was extracted from TGEV-infected IPEC-J2 cells using TRIzol (Invitrogen), according to the manufacturer's instructions. cDNA was synthesized by using HiScript Q RT SuperMix for qPCR (Vazyme, China), according to manufacturer's instructions. Gene expression was measured via quantitative RT-PCR using a TaKaRa SYBR Green qPCR Kit (TaKaRa, Japan). Primers are shown in Table 1. Quantitative real-time PCR was performed with an Applied Biosystems 7500 real-time PCR System. Data were normalized against $\beta$-actin levels and are expressed as fold differences between control and TGEV-infected cells according to the $2^{-\Delta \Delta C T}$ method [30].
Table 1 Primers used for RT-PCR

\begin{tabular}{lll}
\hline Gene & Sequence $\left(\mathbf{5}^{\prime} \mathbf{-} \mathbf{3}^{\prime} \mathbf{)}\right.$ & Size (bp) \\
\hline B-Actin & F: AGATCAAGATCATCGCGCCT & 171 \\
& R: ATGCAACTAACAGTCCGCCT & \\
CAT-1 & F: AGACGGGCTGCTGTTTAAGT & 131 \\
& R: ACCGTTAAAATACCGGCGTG & \\
CAT-2 & F: TGGATGGCACTTGGTTTCCTG & 91 \\
& R: GCAGGTGAAAGGCCTCGTAT & \\
\hline
\end{tabular}

\section{Western blotting}

Protein was obtained from IPEC-J2 cells at the indicated time points post-infection using ice-cold radioimmunoprecipitation assay (RIPA) lysis buffer containing $10 \mathrm{mM}$ phenylmethylsulfonyl fluoride (PMSF). Total protein concentrations were determined using a bicinchoninic acid (BCA) protein assay kit (Thermo Scientific, USA). Cell lysates that contained equal amounts of protein were denatured, subjected to $10 \%$ sodium dodecyl sulfate polyacrylamide gel electrophoresis (SDS-PAGE), and transferred to polyvinylidene difluoride (PVDF) membranes (Millipore, USA). Membranes were blocked with Tris-buffered saline (TBS) containing $5 \%$ nonfat dry milk for $2 \mathrm{~h}$, and incubated with the indicated primary antibodies at $4{ }^{\circ} \mathrm{C}$ overnight. The following antibodies were used in this study: phospho-EGF receptor rabbit mAb (CST, USA); anti-CAT1 (Abcam, UK); caveolin-1 antibody, phospho-PKC $\alpha$ antibody, and $\beta$-tubulin antibody (EnoGene Biotech, USA). The next day, membranes were washed three times with TBST and incubated with HRP-conjugated secondary antibodies for $2 \mathrm{~h}$ at room temperature. The membranes were then washed with TBST for $5 \mathrm{~min}$ four times. Protein band detection was performed using ECL reagents (Thermo Scientific, USA).

\section{Lentivirus-mediated RNA interference (RNAi) depletion experiments}

pLVX-shRNA is an HIV-1-based lentiviral expression vector designed to express a small hairpin RNA (shRNA) for RNA interference (RNAi) studies (Clontech, USA). The target sequences for shRNA were designed from the following sequences: NM_214007 (porcine EGFR), NM_001012613.1 (porcine CAT-1), and NM_214438 (porcine caveolin-1). HEK293T cells were transfected with $1 \mu \mathrm{g}$ of specific expression plasmid per $10^{6}$ cells using the X-tremeGENE HP DNA Transfection Reagent (Roche, Switzerland), diluted in Opti-MEM (Invitrogen) in T-25 cell culture flasks. Lentiviral particles $(\mathrm{MOI}=1)$ were subsequently added to IPEC-J2 cells and gently mixed. 
Arginine detection in cell culture medium using HPLC [31] To measure arginine uptake by IPEC-J2 cells, $100 \mu \mathrm{L}$ of medium was deproteinated with $200 \mu \mathrm{L}$ of trichloroacetate using HPLC. The medium was vortexed and centrifuged at $13000 \mathrm{rpm}$ for $15 \mathrm{~min}$ at $4{ }^{\circ} \mathrm{C}$. Supernatant was recovered using a pipette and purified by passage through a $0.22 \mu \mathrm{m}$ filter. The derivatization procedure was a modification of the method described by Elkin et al. [32]. Next $50 \mu \mathrm{L}$ of the derivatizing reagent acetonitrile-TEA-PITC (8:1:1:1 [v/v]) was added, and the reaction was incubated at room temperature for $60 \mathrm{~min}$. A mixture of $\mathrm{ddH}_{2} \mathrm{O}-$ Hexane $(1 \mathrm{~mL}$ and $0.5 \mathrm{~mL}$ ) was added and incubated for $10 \mathrm{~min}$. Finally the solvents were removed under a nitrogen stream, and the tube was sealed and stored at $4{ }^{\circ} \mathrm{C}$ pending analysis. Chromatography was carried out using a gradient elution at a constant temperature of $40{ }^{\circ} \mathrm{C}$. Eluant A was an aqueous buffer prepared by adding $0.1 \mathrm{~mol} / \mathrm{L}$ sodium acetate solution; Eluant B was acetonitrile. The gradient program is shown in Table 2. Arginine uptake was calculated as follows: arginine uptake $(\mathrm{mg} / \mathrm{L}$ per $10^{6}$ cells $)=($ arginine concentration of the control group-arginine concentration of the experimental group)/cell number.

\section{Statistical analysis}

All results are expressed as the means \pm standard deviations (SD) from three independent experiments. Significant differences between control and experimental groups were analyzed using Student's $t$-test. Difference were considered significant at ${ }^{*} 0.01<p<0.05,{ }^{* *} p<0.01$.

\section{Results}

TGEV infection decreases arginine uptake

The uptake of arginine was quantified by HPLC after calibrating the assay using arginine standards (Figure 1A) and preparing a standard curve (data not shown). TGEV infection had no effect on the uptake of arginine at $12 \mathrm{~h}$ and $24 \mathrm{~h}$. Arginine uptake began to decrease at $36 \mathrm{~h}$, and was significantly lower at $48 \mathrm{~h}$ and $60 \mathrm{~h}$ (Figure 1B).

\section{TGEV infection reduces CAT-1 expression}

Arginine uptake is mediated by the CAT family of transporters. mRNA levels of CAT-1 and CAT-2 were quantified by RT-PCR. Expression of CAT-1 markedly decreased at $48 \mathrm{~h}$ and $60 \mathrm{~h}$, while mRNA levels of CAT-2 did not change significantly (Figures $2 \mathrm{~A}$ and B). Expression of CAT-1 protein was consistent with CAT-1 mRNA expression (Figure 2C).

\section{PKC $a$ is involved in arginine uptake}

PKC $\alpha$ is involved in the regulation of CAT- 1 transport activity [33]. Our results showed the activation of p-PKC $\alpha$ after TGEV infection at $48 \mathrm{~h}$ (Figure 3A). To further investigate whether PKC $\alpha$ was responsible for CAT-1 expression and arginine uptake, we used phorbol 12-myristate 13-acetate (PMA), a classical activator of PKC $\alpha$. TGEV-infected IPEC-J2 cells that were treated with PMA for $12 \mathrm{~h}$ exhibited significant activation of p-PKC $\alpha$, and also a noticeable decrease of CAT-1 (Figure $3 \mathrm{~B})$. The uptake of arginine was also dramatically reduced after treatment with PMA (Figure $3 \mathrm{C}$ ).

Table 2 Gradient program employed for the separation of PTC-amino acids

\begin{tabular}{lrrrrrrrrrrrr}
\hline Time (min) & $\mathbf{0}$ & $\mathbf{1 0}$ & $\mathbf{2 0}$ & $\mathbf{2 1}$ & $\mathbf{3 4}$ & $\mathbf{3 5}$ & $\mathbf{4 3}$ & $\mathbf{4 4}$ & $\mathbf{4 9}$ & $\mathbf{5 3}$ \\
\hline $\mathrm{A} \%(\mathrm{~V} / \mathrm{V})$ & 95 & 91 & 89 & 79 & 77 & $\mathbf{7 5}$ & 68 & 20 & 10 & 95 \\
$\mathrm{~B} \%(\mathrm{~V} / \mathrm{V})$ & 5 & 9 & 11 & 21 & 23 & 25 & 32 & 80 & 90 & 5 \\
\hline
\end{tabular}

A

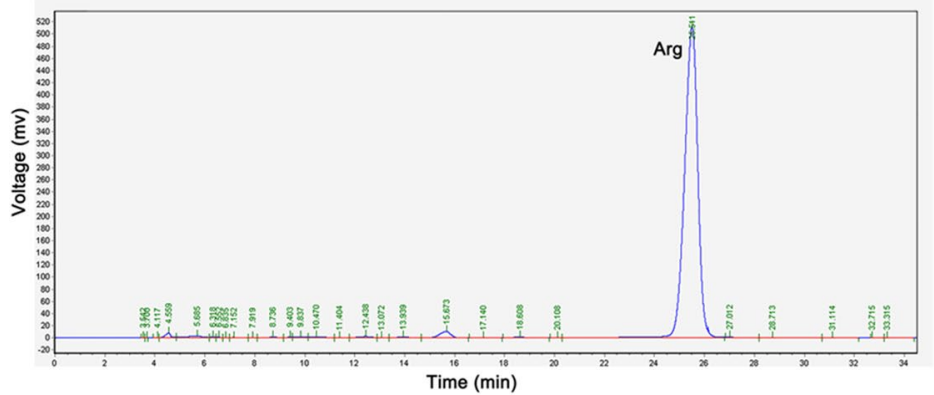

B

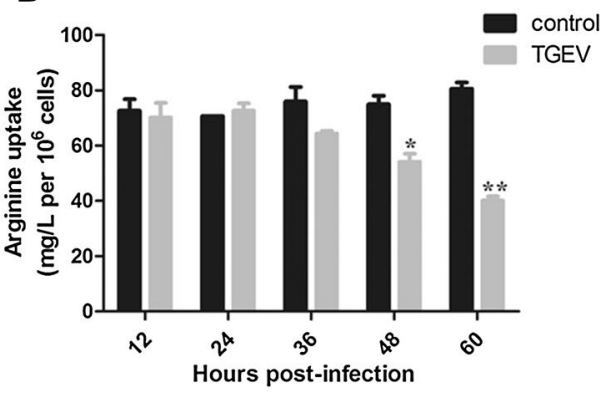

Figure 1 TGEV infection decreases arginine uptake. A HPLC analysis of a purified sample of arginine used as a standard. B IPEC-J2 cells were incubated with TGEV $(\mathrm{MOI}=3)$, and culture supernatants were collected for arginine analysis at the indicated time points. Results are expressed as means \pm SDs of three independent experiments. Differences were considered significant at ${ }^{*} 0.01<p<0.05,{ }^{* *} p<0.01$. 

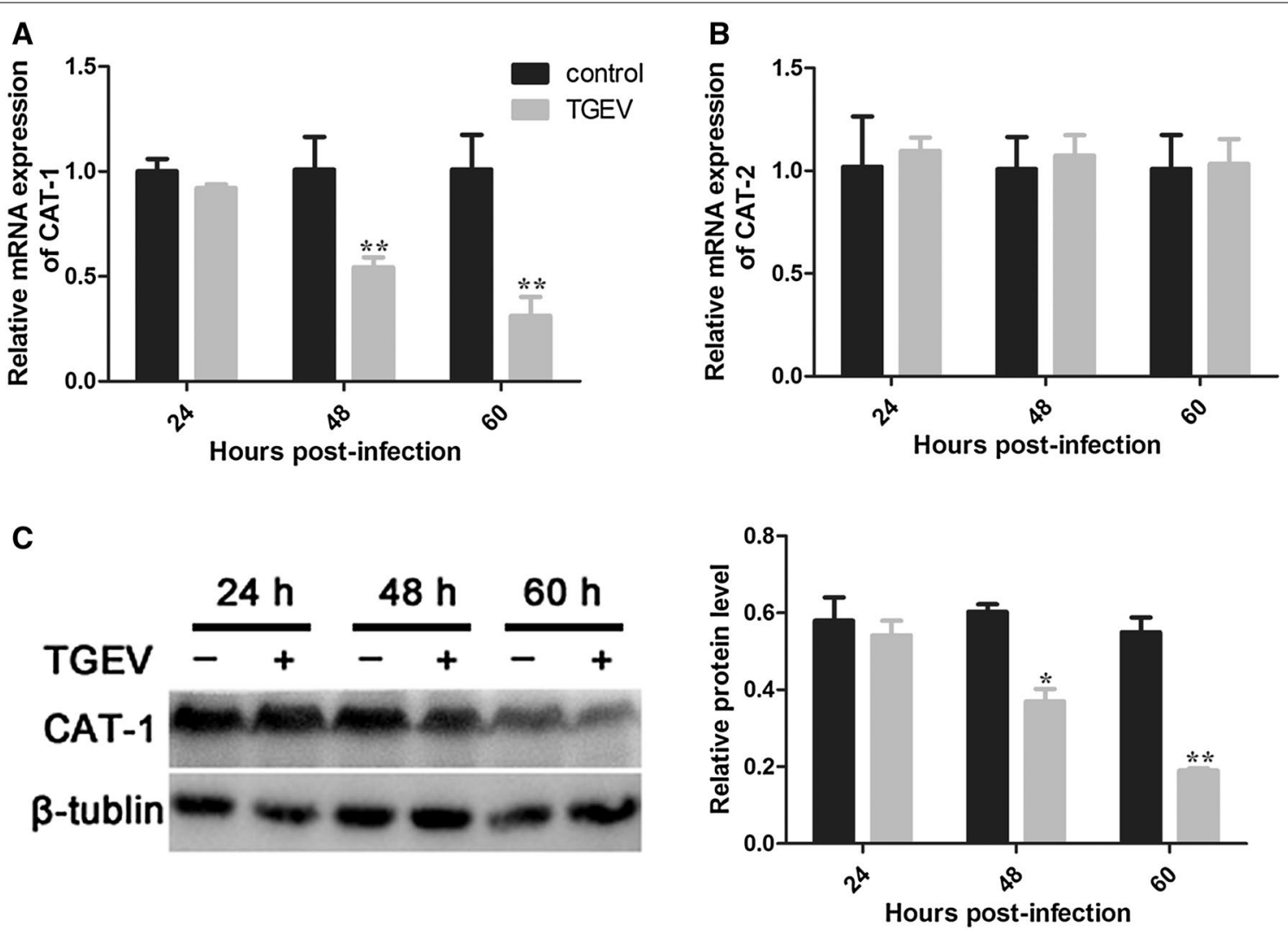

Figure 2 TGEV infection decreases expression of CAT-1. A, B Relative mRNA expression for CAT-1 and CAT-2, determined using RT-PCR. C Western blot analysis of CAT-1 protein levels. Differences were considered significant at ${ }^{*} 0.01<p<0.05,{ }^{* *} p<0.01$.
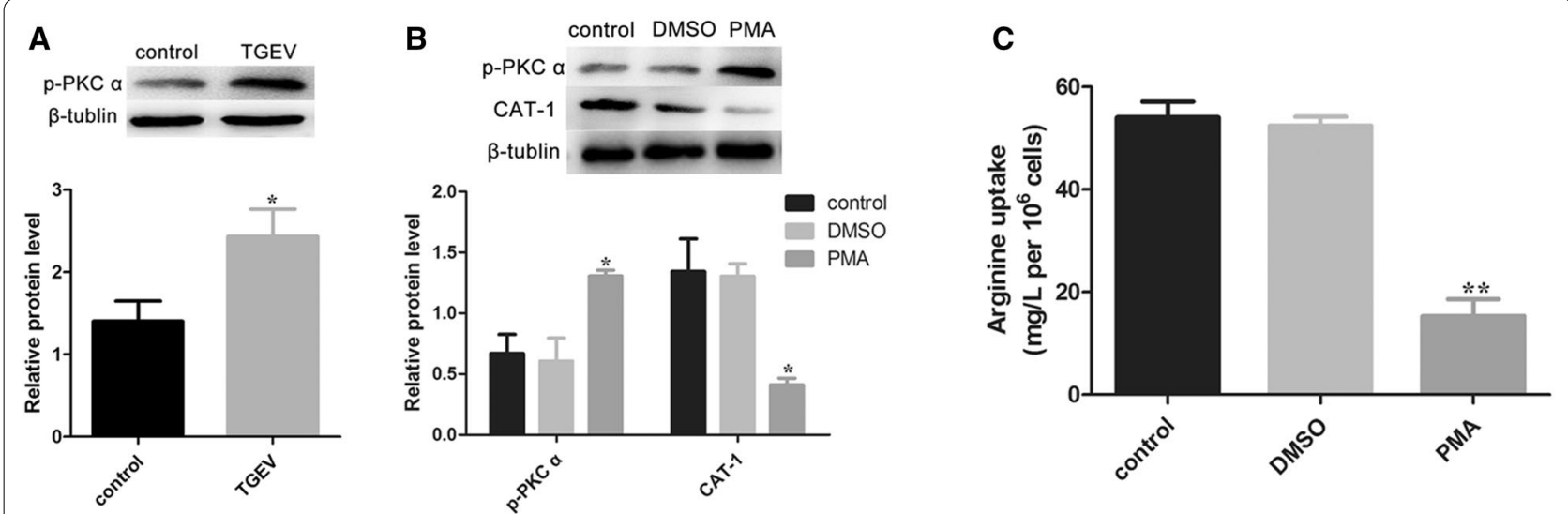

Figure 3 TGEV infection activates p-PKC $a$ and PKC a influences arginine uptake. A Protein levels of p-PKC a were analyzed by Western blot at $48 \mathrm{hpi}$. B Cells pre-infected with TGEV were treated with PBS, DMSO (100 nM), or PMA (100 nM) for $12 \mathrm{~h}$. Expression of p-PKC a and CAT-1 was analyzed. C Arginine uptake was assayed. Differences were considered significant at ${ }^{*} 0.01<p<0.05,{ }^{* *} p<0.01$.

EGFR regulates CAT-1 and arginine uptake

PKC acts as the downstream target of EGFR signaling, and can be regulated by EGFR [34, 35]. We therefore analyzed the expression level of p-EGFR. As expected,
TGEV infection markedly induced activation of p-EGFR (Figure 4A). AG1478, an inhibitor of EGFR, was used to determine whether EGFR was involved in the process. As shown in Figure 4B, AG1478 showed a decrease of 


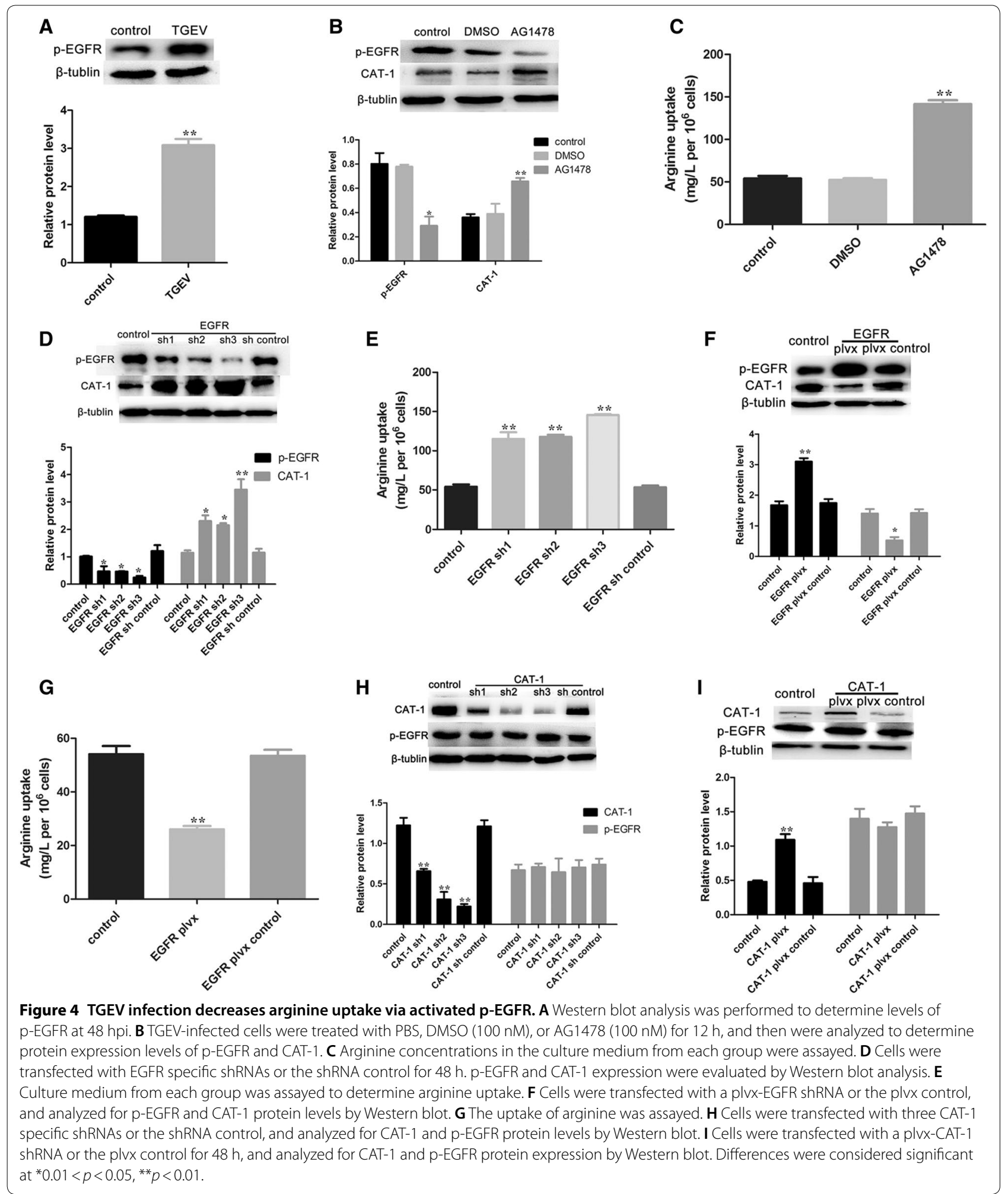

p-EGFR, while CAT-1 expression was promoted. Moreover, arginine uptake was increased after TGEV-infected cells were treated with AG1478 (Figure 4C).
To study the relationship between EGFR and CAT-1, we manipulated EGFR and CAT-1 expression in knockdown and overexpression experiments. EGFR-targeting 
shRNAs significantly inhibited p-EGFR expression, but expression of CAT-1 increased (Figure 4D). Arginine uptake also increased after transfecting with EGFR-targeting shRNAs (Figure 4E). In contrast, cells transfected with plvx-EGFR had higher p-EGFR expression, lower CAT-1 expression, and decreased arginine uptake (Figures 4F and G). TGEV-infected cells transfected with CAT-1 specific shRNAs exhibited reduced CAT-1 expression but no effects on EGFR (Figure 4H). Transfection with plvx-CAT-1 resulted in higher levels of CAT-1 but left EGFR unchanged (Figure 4I). Taken together, these results indicated that TGEV infection activates p-EGFR, which modulates CAT-1 and thereby affects arginine uptake.

\section{Caveolin-1 participates in arginine uptake}

Figure 5A shows that TGEV infection increased caveolin-1 expression. Caveolin-1 knockout suppressed the expression of caveolin-1, while increasing CAT-1 protein expression and arginine uptake (Figures $5 B$ and $C$ ). Transfection with CAT-1-targeting shRNAs resulted in higher caveolin-1 protein expression than in control

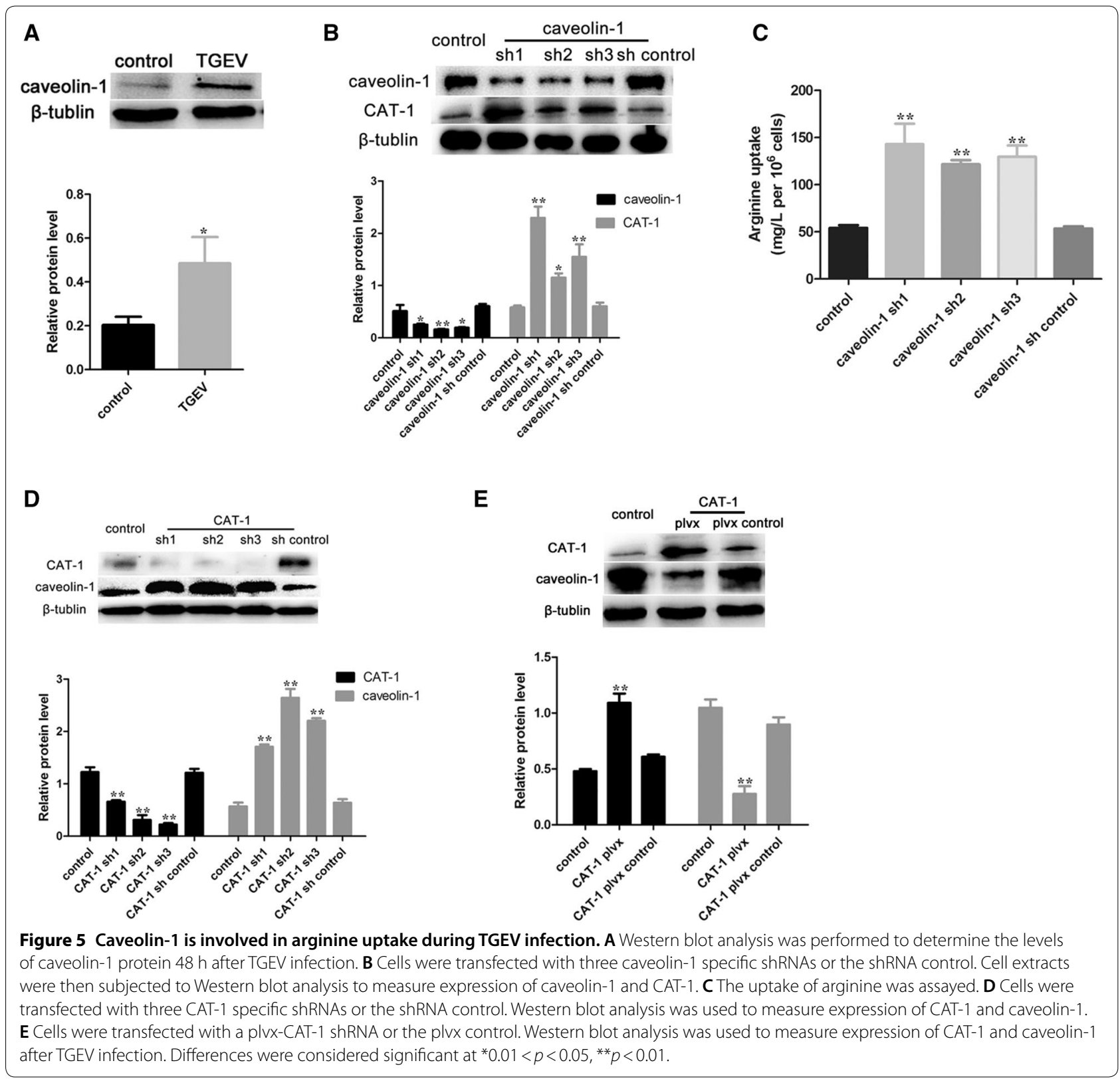




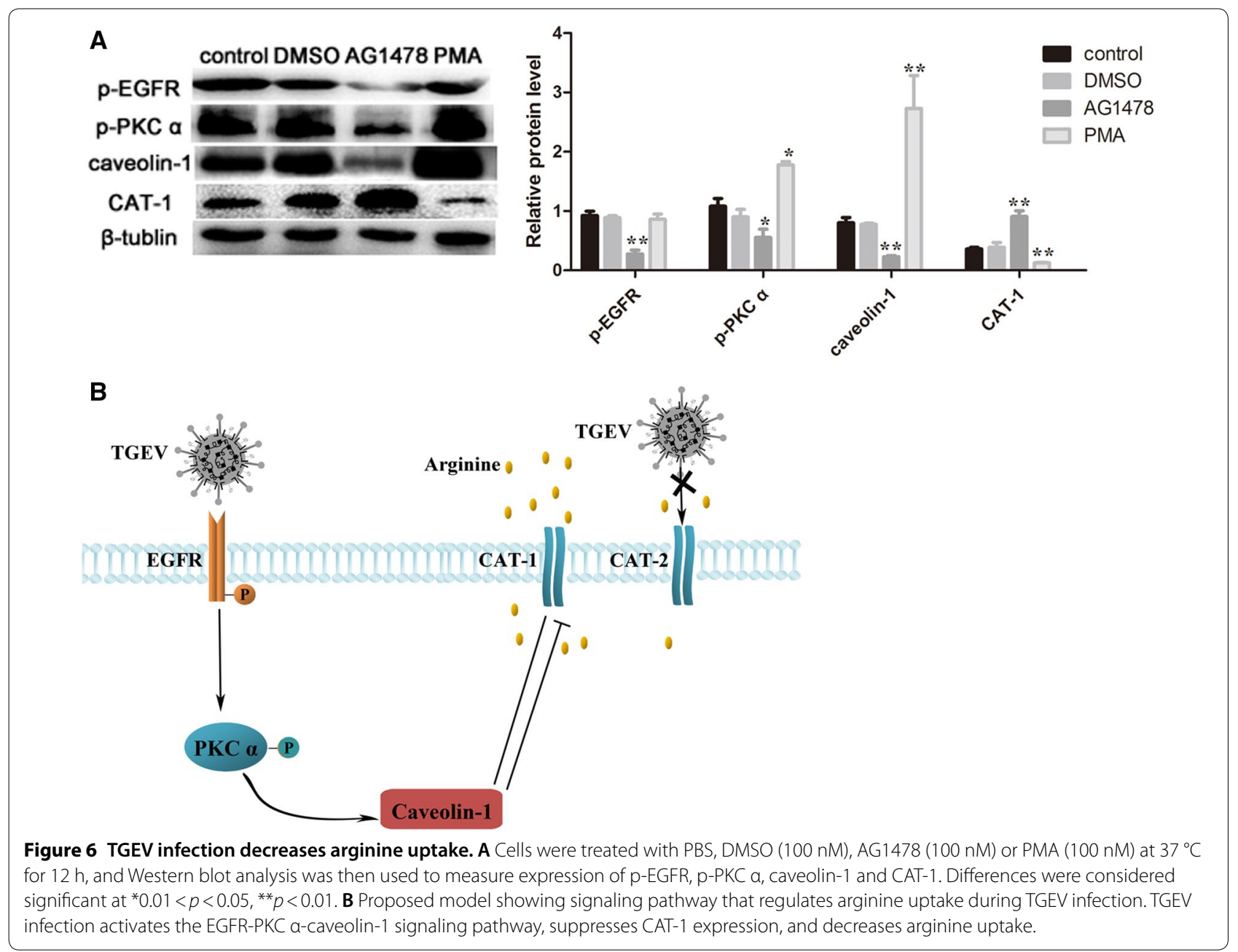

cells (Figure 5D), and plvx-CAT-1 had the opposite effect (Figure 5E).

\section{A signaling cascade regulates arginine uptake during TGEV infection}

Finally, we explored the relationships between EGFR, PKC $\alpha$, caveolin-1, and CAT-1 to probe their behavior as a signaling pathway. As shown in Figure 6A, treatment of cells with EGFR inhibitor (AG1478) resulted in inhibition of p-EGFR, p-PKC $\alpha$, and decreased caveolin-1 protein expression, and higher CAT-1 expression. PMA (a PKC $\alpha$ activator) had no influence on p-EGFR, while it increased p-PKC $\alpha$ and caveolin-1, and decreased CAT-1 expression.

\section{Discussion}

Arginine is an essential amino acid in mammals and plays an important role in tissue growth. In the present study, we showed that TGEV infection decreased the uptake of arginine in IPEC-J2 cells. Although four CAT proteins
(CAT-1, CAT-2, CAT-3, and CAT-4) mediate arginine transport, only CAT- 1 and CAT- 2 are expressed in porcine intestinal epithelial cells. It has been demonstrated that CAT-1 is a higher-affinity carrier for cationic amino acids, and has more pronounced trans stimulation compared with CAT-2 $[8,36]$. Our experiments showed that expression of CAT-1 was consistent with the trends of arginine uptake, while CAT- 2 mRNA levels remained unchanged. These results suggest that CAT- 1 may play an important role in mediating arginine uptake during TGEV infection.

Previous studies demonstrated that PKC $\alpha$ acts as a regulator of CAT-1 transporter activity in cells [21]. PKC $\alpha$ activity is controlled by phosphorylation, and activation of PKC $\alpha$ leads to down-regulation of CAT-1 at the cell surface [37]. Treatment with PMA, a PKC stimulant, decreased the uptake of arginine and the expression of CAT-1. Consistent with results reported by Schwartz et al., the modulation of CAT-1 was associated with 
$\mathrm{p}-\mathrm{PKC} \alpha$ [38]. We therefore conclude that p-PKC $\alpha$ influences the transport activity of CAT-1.

EGFR belongs to the receptor tyrosine kinase (RTK) family and is activated by many viruses [27, 39]. Activated EGFR triggers numerous downstream signaling pathways, including PKC-mediated cascades, and activates Ras, which affects various MAP kinases [40]. Hu et al. demonstrated that EGFR influences TGEV entry, and plays a synergistic role with APN early in TGEV infection. TGEV acts via the EGFR-PI3 K-Rac1/Cdc42PAK-LIMK signaling pathway to regulate coflin activity and F-actin arrangement early in infection, and promotes TGEV entry [27]. Further research showed EGFR acts as a co-factor for TGEV entry, and TGEV S1 protein is able to bind to EGFR [28]. Moreover, EGFR is also involve in the regulation of glucose uptake during TGEV infection [41]. Our data provide evidence that EGFR regulates arginine uptake by functioning as a signal molecule in an EGFR-PKC $\alpha$-caveolin-1-CAT-1 signaling pathway in TGEV-infected cells (Figure 6B). Our model includes a previously unreported signaling pathway that links EGFR with CAT-1. However, it is not yet known how EGFR passes a signal to CAT-1, or if other as yet unidentified signaling molecules regulate CAT-1.

Both PKC and CAT-1 are located in the caveola, suggesting that caveolin-1 may be involved in arginine uptake. Caveolin-1 is the main protein component of caveolae, and is necessary for caveolae formation [42]. CAT-1 and caveolin-1 were reported to co-localize on the surface of cells. Our results showed that increased caveolin-1 levels are involved in the regulation of CAT1. A possible explanation is that TGEV infection promotes CAT-1 clustering to caveolae islands, resulting in co-location.

In conclusion, we found that TGEV infection induces activation of p-EGFR and p-PKC $\alpha$, enhances the expression of caveolin-1, attenuates CAT-1 expression, and decreases arginine uptake in IPEC-J2 cells. This study furthers our understanding of the mechanisms of TGEV infection, and is the first description of TGEV infection and amino acid uptake in vitro.

\begin{abstract}
Abbreviations
TGEV: transmissible gastroenteritis virus; HPLC: high performance liquid chromatography; hpi: hours post-infection; CAT-1: cationic aino acid transporter 1; PKC: protein kinase C; EGFR: epidermal growth factor receptor; IPEC-J2: porcine small intestinal epithelial cell line; DMEM: Dulbecco's modified Eagle's medium; FBS: fetal bovine serum; MOI: multiplicity of infection; PBS: phosphate-buffered saline; SDS-PAGE: sulfate polyacrylamide gel electrophoresis; RNAi: RNA interference; PMA: phorbol 12-myristate 13-acetate.
\end{abstract}

\section{Competing interests}

The authors declare that they have no competing interests.

\section{Authors' contributions}

LX designed and performed the experiments, analyzed the data, and wrote the manuscript; LD participated in designing and conducting the experiments, and analyzing the data; QY participated in experiment design and supervised the experiments. All authors read and approved the final manuscript.

\section{Acknowledgements}

This work was supported by 31772777 from the National Science Grant of China and a project funded by the Priority Academic Program Development of Jiangsu Higher Education Institutions (PAPD).

\section{Publisher's Note}

Springer Nature remains neutral with regard to jurisdictional claims in published maps and institutional affiliations.

Received: 8 May 2018 Accepted: 10 September 2018

Published online: 20 September 2018

\section{References}

1. Hou Y, Yue X, Cai X, Wang S, Liu Y, Yuan C, Cui L, Hua X, Yang Z (2012) Complete genome of transmissible gastroenteritis virus AYU strain isolated in Shanghai, China. J Virol 86:11935

2. Man CL, Yu XL (2011) New mutations existing in the nucleocapsid (N) gene of non-porcine TGEV strains isolated in China. Afr J Microbiol Res 5:5325-5332

3. Zhou J, Huang F, Hua X, Cui L, Zhang W, Shen Y, Yan Y, Chen P, Ding D, Mou J, Chen Q, Lan D, Yang Z (2010) Inhibition of porcine transmissible gastroenteritis virus (TGEV) replication in mini-pigs by shRNA. Virus Res 149:51-55

4. Sun RQ, Cai RJ, Chen YQ, Liang PS, Chen DK, Song CX (2012) Outbreak of porcine epidemic diarrhea in suckling piglets, China. Emerg Infect Dis 18:161-163

5. Brosnahan AJ, Brown DR (2012) Porcine IPEC-J2 intestinal epithelial cells in microbiological investigations. Vet Microbiol 156:229-237

6. Zhao S, Gao J, Zhu L, Yang Q (2014) Transmissible gastroenteritis virus and porcine epidemic diarrhoea virus infection induces dramatic changes in the tight junctions and microfilaments of polarized IPEC-J2 cells. Virus Res 192:34-45

7. Xia M, Ye L, Hou Q, Yu Q (2016) Effects of arginine on intestinal epithelial cell integrity and nutrient uptake. Br J Nutr 14:1-7

8. Hatzoglou M, Fernandez J, Yaman I, Closs E (2004) Regulation of cationic amino acid transport: the story of the CAT-1 transporter. Annu Rev Nutr 24:377-399

9. Bronte V, Zanovello P (2005) Regulation of immune responses by L-arginine metabolism. Nat Rev Immunol 5:641-654

10. Wu G (2010) Functional amino acids in growth, reproduction, and health. Adv Nutr 1:31-37

11. Wu G (2009) Amino acids: metabolism, functions, and nutrition. Amino Acids $37: 1-17$

12. Tesseraud S, Metayer Coustard S, Collin A, Seiliez I (2009) Role of sulfur amino acids in controlling nutrient metabolism and cell functions: implications for nutrition. Br J Nutr 101:1132-1139

13. Wu GY, Bazer FW, Davis TA, Jaeger LA, Johnson GA, Kim SW, Knabe DA, Meininger CJ, Spencer TE, Yin YL (2007) Important roles for the arginine family of amino acids in swine nutrition and production. Livest Sci $112: 8-22$

14. Wijnands KA, Castermans TM, Hommen MP, Meesters DM, Poeze M (2015) Arginine and citrulline and the immune response in sepsis. Nutrients 7:1426-1463

15. Fotiadis D, Kanai Y, Palacin M (2013) The SLC3 and SLC7 families of amino acid transporters. Mol Aspects Med 34:139-158

16. Poncet N, Taylor PM (2013) The role of amino acid transporters in nutrition. Curr Opin Clin Nutr Metab Care 16:57-65

17. He LQ, Yang HS, Hou YQ, Li TJ, Fang J, Zhou XH, Yin YL, Wu L, Nyachoti M, Wu GY (2013) Effects of dietary L-lysine intake on the intestinal mucosa and expression of CAT genes in weaned piglets. Amino Acids 45:383-391 
18. Rotmann A, Strand D, Martine U, Closs El (2004) Protein kinase C activation promotes the internalization of the human cationic amino acid transporter hCAT-1. A new regulatory mechanism for hCAT-1 activity. J Biol Chem 279:54185-54192

19. Kim MO, Lee YJ, Park JH, Ryu JM, Yun SP, Han HJ (2012) PKA and CAMP stimulate proliferation of mouse embryonic stem cells by elevating GLUT1 expression mediated by the NF-kappaB and CREB/CBP signaling pathways. Biochim Biophy Acta 1820:1636-1646

20. Leventhal PS, Bertics PJ (1993) Activation of protein kinase C by selective binding of arginine-rich polypeptides. J Biol Chem 268:13906-13913

21. Krotova KY, Zharikov SI, Block ER (2003) Classical isoforms of PKC as regulators of CAT-1 transporter activity in pulmonary artery endothelial cells. Am J Physiol Lung Cell Mol Physiol 284:L1037-L1044

22. Mann GE, Yudilevich DL, Sobrevia L (2003) Regulation of amino acid and glucose transporters in endothelial and smooth muscle cells. Physiol Rev 83:183-252

23. Laplante M, Sabatini David M (2012) mTOR signaling in growth control and disease. Cell 149:274-293

24. Pan M, Meng Q, Wolfgang CL, Lin C, Karinch AM, Vary TC, Souba WW (2002) Activation of intestinal arginine transport by protein kinase $c$ is mediated by mitogen-activated protein kinases. J Gastrointest Surg 6:876-882

25. Kanashiro Celia A, Khalil Raouf A (2007) Signal transduction by protein kinase $C$ in mammalian cells. Clin Exp Pharmacol Physiol 25:974-985

26. Pan M, Stevens BR (1995) Protein kinase C-dependent regulation of L-arginine transport activity in Caco-2 intestinal cells. Biochim Biophys Acta 1239:27-32

27. Hu W, Zhu L, Yang X, Lin J, Yang Q (2016) The epidermal growth factor receptor regulates cofilin activity and promotes transmissible gastroenteritis virus entry into intestinal epithelial cells. Oncotarget 7:12206-12221

28. Hu W, Zhang S, Shen Y, Yang Q (2018) Epidermal growth factor receptor is a co-factor for transmissible gastroenteritis virus entry. Virology 521:33-43

29. Weiwei H, Qinghua Y, Liqi Z, Haofei L, Shanshan Z, Qi G, Kongwang H, Qian Y (2014) Complete genomic sequence of the coronavirus transmissible gastroenteritis virus SHXB isolated in China. Arch Virol 159:2295-2302

30. Livak KJ, Schmittgen TD (2001) Analysis of relative gene expression data using real-time quantitative PCR and the $2^{-\triangle \Delta C T}$ method. Methods 25:402-408

31. Martens-Lobenhoffer J, Bode-Boger SM (2006) Fast and efficient determination of arginine, symmetric dimethylarginine, and asymmetric dimethylarginine in biological fluids by hydrophilic-interaction liquid chromatography-electrospray tandem mass spectrometry. Clin Chem 52:488-493

32. Elkin RG, Wasynczuk AM (1987) Amino acid analysis of feedstuff hydrolysates by precolumn derivatization with phenylisothiocyanate and reversed-phase high-performance liquid chromatography. Cereal Chem 64:226-229

33. Vina-Vilaseca A, Bender-Sigel J, Sorkina T, Closs El, Sorkin A (2011) Protein kinase C-dependent ubiquitination and clathrin-mediated endocytosis of the cationic amino acid transporter CAT-1. J Biol Chem 286:8697-8706

34. Bae JH, Kim SJ, Kim MJ, Oh SO, Chung JS, Kim SH, Kang CD (2012) Susceptibility to natural killer cell-mediated lysis of colon cancer cells is enhanced by treatment with epidermal growth factor receptor inhibitors through UL16-binding protein-1 induction. Cancer Sci 103:7-16

35. Lee HY, Crawley S, Hokari R, Kwon S, Kim YS (2010) Bile acid regulates MUC2 transcription in colon cancer cells via positive EGFR/PKC/Ras/ERK/ CREB, PI3K/Akt/I kappa B/NF-kappa B and p38/MSK1/CREB pathways and negative JNK/c-Jun/AP-1 pathway. Int J Oncol 36:941-953

36. Kanda M, Matthaei H, Wu J, Hong SM, Yu J, Borges M, Hruban RH, Maitra A, Kinzler K, Vogelstein B, Goggins M (2012) Presence of somatic mutations in most early-stage pancreatic intraepithelial neoplasia. Gastroenterology 142:730

37. Parekh DB, Ziegler W, Parker PJ (2000) Multiple pathways control protein kinase C phosphorylation. EMBO J 19:496-503

38. Schwartz IF, Grupper A, Soetendorp H, Hillel O, Laron I, Chernichovski T, Ingbir M, Shtabski A, Weinstein T, Chernin G, Shashar M, Hershkoviz R, Schwartz D (2012) Attenuated glomerular arginine transport prevents hyperfiltration and induces HIF-1alpha in the pregnant uremic rat. Am J Physiol Renal Physiol 303:F396-F404

39. Kung CP, Raab-Traub N (2010) Epstein-Barr virus latent membrane protein 1 modulates distinctive NF-kappaB pathways through C-terminus-activating region 1 to regulate epidermal growth factor receptor expression. J Virol 84:6605-6614

40. Grahovac J, Wells A (2014) Matrikine and matricellular regulators of EGF receptor signaling on cancer cell migration and invasion. Lab Invest 94:31-40

41. Dai L, Hu WW, Xia L, Xia M, Yang Q (2016) Transmissible gastroenteritis virus infection enhances SGLT1 and GLUT2 expression to increase glucose uptake. PLoS One 11:e0165585

42. Frank PG (2010) Endothelial caveolae and caveolin-1 as key regulators of atherosclerosis. Am J Pathol 177:544-546
Ready to submit your research? Choose BMC and benefit from:

- fast, convenient online submission

- thorough peer review by experienced researchers in your field

- rapid publication on acceptance

- support for research data, including large and complex data types

- gold Open Access which fosters wider collaboration and increased citations

- maximum visibility for your research: over 100M website views per year

At $\mathrm{BMC}$, research is always in progress.

Learn more biomedcentral.com/submissions 